\title{
O ensino de fotografia no curso de Medicina Veterinária
}

\section{Teaching photograph in Veterinary Course}

\author{
Milton Hissashi Yamamura ${ }^{*}$; Maria Irene Pellegrino de Oliveira Souza ${ }^{2}$
}

\section{Resumo}

O artigo aborda o ensino da fotografia no curso de Medicina Veterinária. Considerando que a Ciência Veterinária é rica nas produções e utilizações imagéticas, incluindo a fotografia, que podem ser obtidas através das diferentes objetivas e equipamentos fotográficos, e quando estes são acoplados em outros equipamentos que magnificam os espécimes fotografados, com o uso de diferentes tipos de microscópios ópticos e eletrônicos. Esse material produzido é utilizado nas aulas como elemento enriquecedor da aprendizagem através do olhar e nas ilustrações e divulgações dos resultados de pesquisas em eventos e publicações científicas. Tais imagens asseveram a veracidade dos resultados da pesquisa e também servem como ilustrações do campo editorial veterinário; propiciando a professores e alunos deste curso material visual e impresso de boa qualidade para o exercício do olhar, tornando-os mais humanistas e sensíveis.

Palavras-chave: Fotografia, ensino, Medicina veterinária, fotografia científica

\begin{abstract}
This article is focused on teaching photograph in Veterinary course. Talking into account that the Veterinary Science is rich in production and use of images, including photograph, which can be obtained by means of different lenses and kinds of photographic equipment, and when such equipment is attached to other equipment, different kind of optical and electronic microscopes, the photographed species is magnified, it is considered that such materials are useful for teaching, illustrating scientific events and publication, such as veterinary scientific magazines and books. Photographies not only ratify the veracity of the research finding, but their use also provides better visual material for classes and scientific events, giving teachers and students the opportunity to become more humanist and sensitive through the practice of looking at the images.
\end{abstract}

Key words: Photograph, teaching, Veterinary scholl, scientific photograph

1 Especialista em Fotografia pela Universidade Estadual de Londrina e Professor Titular do Departamento de Medicina Veterinária da Universidade Estadual de Londrina. E-mail: yamamura@uel.br.

2 Especialista em Fotografia e mestre em Educação pela Universidade Estadual de Londrina e Doutora pela Universidade Estadual de Campinas, Professora do curso de Especialização em Fotografia da Universidade Estadual de Londrina.

* Autor para correspondência 


\section{O Ensino da Fotografia na Medicina Veterinária}

O curso de Medicina Veterinária tem como objetivo específico e final a formação de um profissionalgeneralista, humanista, críticoereflexivo, apto a compreender e traduzir as necessidades de indivíduos, grupos sociais e comunidades em relação às atividades inerentes ao exercício profissional. A profissão de médico veterinário esta regulamentada pela lei numero 5517, e pelo decreto numero 64704 , de 17 de junho de 1969. Os campos específicos de atuação são: a saúde animal, medicina veterinária preventiva, inspeção de produtos de origem animal e clínicas veterinárias; atua ainda em saneamento ambiental, tecnologia de produtos de origem animal, saúde pública, em toda a área zootécnica, produção e reprodução animal; ecologia e proteção ao meio ambiente. O profissional deve ter a capacidade de raciocínio lógico, de observação, de interpretação e de análise de dados e informações, bem como dos conhecimentos essenciais de Medicina Veterinária para identificação e resolução de problemas. Portanto o objetivo geral do curso é dotar o profissional dos conhecimentos necessários para desenvolver ações nas áreas de produção animal, produção de alimentos, saúde animal e proteção ambiental, com competência e habilidade para dar atenção à saúde, tomar decisões, comunicar-se, liderar, administrar e gerenciar, buscar a educação permanente. Para isso, a Resolução $n^{\circ} .1$ de 18 de fevereiro de 2003 do Conselho Nacional da Educação instituiu Diretrizes Curriculares Nacionais dos Cursos de Graduação em Medicina Veterinária. Os conteúdos essenciais para o Curso de Graduação em Medicina Veterinária devem levar em conta a formação generalista do profissional e os conteúdos devem contemplar:

I - Ciências Biológicas e da Saúde - incluem-se os conteúdos (teóricos e práticos) de bases moleculares e celulares dos processos normais e alterados, da estrutura e função dos tecidos, órgãos, sistemas e aparelhos, bem como processos bioquímicos, biofísicos, microbiológicos, imunológicos, genética molecular ebioinformática em todo desenvolvimento do processo saúde-doença, inerentes à Medicina Veterinária.

II - Ciências Humanas e Sociais - incluem-se os conteúdos referentes às diversas dimensões da relação indivíduo/sociedade, contribuindo para a compreensão dos determinantes sociais, culturais, comportamentais, psicológicos, ecológicos, éticos e legais e conteúdos envolvendo a comunicação, a informática, a economia e gestão administrativa em nível individual e coletivo.

III - Ciências da Medicina Veterinária - incluemse os conteúdos teóricos e práticos relacionados com saúde-doença, produção animal e ambiente, com ênfase nas áreas de Saúde Animal, Clínica e Cirurgias Veterinárias, Medicina Veterinária Preventiva, Saúde Pública, Zootecnia, Produção Animal e Inspeção e Tecnologia de Produtos de Origem Animal, contemplando os conteúdos teóricos e práticos a seguir:

a) Zootecnia e Produção Animal - envolvendo sistemas de criação, manejo, nutrição, biotécnicas da reprodução, exploração econômica e ecologicamente sustentável, incluindo agro negócio.

b) Inspeção e Tecnologia dos Produtos de Origem Animal-incluindo classificação, processamento, padronização, conservação e inspeção higiênica e sanitária dos produtos de origem animal e dos seus derivados.

c) Clínica Veterinária - incorporando conhecimentos de clínica, cirurgia e fisiopatologia da reprodução com ênfase nos aspectos semiológicos e laboratoriais, visando a determinação da etiopatogenia, do diagnóstico e dos tratamentos médico ou cirúrgico das enfermidades de diferentes naturezas.

d) Medicina Veterinária Preventiva e Saúde Pública reunindo conteúdos essenciais às atividades destinadas ao planejamento em saúde, a epidemiologia, controle e erradicação das enfermidades infecto-contagiosas, parasitárias 
e zoonoses, saneamento ambiental, produção e controle de produtos biológicos.

Desde os tempos dos primitivos homens caçadores surgiram artistas pintores, escultores e gravadores, demonstrando o desejo de expressar através das artes, isso é algo inerente ao ser humano. As pinturas eram vibrantes realizadas em policromia e tinham o firme propósito de imitar a natureza com o realismo a partir das observações efetuadas durante a caçada. Em alguns pontos vitais do animal eram marcados com flechas para garantir o êxito do caçador. Normalmente os desenhos são formados por figuras de grandes animais selvagens, como bisões, cavalos, cervos e quando o homem está presente está representado nas atividades de dança e caça.

Camargo (1997) chama de imagem documental quando registra e traduz com grande margem de similaridade a fonte do qual se origina e as condições em que foi realizada. Quando possui um alto grau de especularidade em relação ao que, ou quem, onde e quando foi obtida, possibilitando a recuperação total ou em grande parte da informação original. A principal função das imagens documentais é sua veracidade, sua capacidade de registrar aquilo que é, onde, quando e como foi, é ou está. Elas nos permitem julgar, avaliar, ponderar, diagnosticar, constatar, prever, prevenir. Elas relatam situações vividas ou testemunhadas e servem de referência para que possamos identificar ou conhecer melhor algo que não temos acesso e queremos descobrir ou comprovar. Em todas as áreas da Medicina Veterinária, seja a básica ou a profissionalizante, a prática do olhar está presente, na tentativa de trazer o real para a sala de aula, principalmente com o uso da fotografia nas aulas teóricas, seminários, mesa redonda e discussão em grupos ministrados pelos docentes e discentes. São poucos os cursos de Medicina Veterinária que oferecem o ensino da fotografia no seu curso de graduação e pós-graduação, seja lato senso ou strito senso, e o interesse maior dos docentes que atuam nas diferentes áreas da veterinária é a apresentação de um melhor material visual didático, que facilite o aprendizado, bem como melhorar a visão do mundo.

Sontag (1981), diz que ao nos ensinar um novo código, a fotografia transforma e amplia nossas noções sobre o que vale a pena olhar e o que efetivamente podemos observar. Constitui ela uma gramática e o que é mais importante, uma ética de ver. Torna-se evidente que áreas que desenvolvem mais atividades de pesquisas dão suportes para criações de materiais audiovisuais, incluindo a fotografia. Estas experiências individuais ou de grupos são levadas na forma de mensagens visuais para as salas de aulas e laboratórios, para aguçar o sentido do olhar do discente de graduação e pósgraduação. Quando a informatização não estava presente no sistema educacional e de pesquisa, o uso de filme cromo era o principal recurso para ilustrações nas aulas e apresentações científicas em revistas e eventos, bem como material ilustrativo no campo editorial, pela precisão necessária no registro fiel que se obtinha desta película. E o filme preto e branco era utilizado para ilustrações de publicações em revistas especializadas e no campo editorial, porque as fotos coloridas tinham preços bastante elevados quando inseridos nas publicações em revistas nacionais e internacionais.

Em consultas realizadas com os vinte alunos da pós-graduação em Ciência Animal da Universidade Estadual de Londrina, procedentes dos diferentes cursos de Medicina Veterinária e Zootecnia, como da Universidade Estadual de Londrina, Universidade Federal do Paraná, campus Palotina, Universidade do Desenvolvimento de Santa Catarina, Universidade Paulista, campus de Jaboticabal e Universidade Federal de Lavras, constatou que o emprego de imagens e fotografias é comum em quase todas as matérias destes cursos. A disciplina Diagnóstico por Imagens tem o uso essencialmente da imagem nas suas aulas e esta pode ser através das análises de imagens de Raio X ou por ultra-sonografia, que usam a forma negativa. Nas disciplinas cujas ementas constam o item diagnóstico para identificação de agentes 
etiológicos, há o emprego de imagens e fotografia, estas obtidas principalmente pela fotomicrografia, podendo também ter macro e microfotografia, que ilustram as aulas teóricas e confirmadas nas aulas práticas através da visualização destes agentes em lâminas de vidro preparados ou espécimes mantidos em liquido conservador.

A Medicina Veterinária, tanto nas suas áreas de atuações, como produção animal, sanidade e clínicas e cirurgia dos animais, necessitam de todos os tipos de fotografias, desde a fotografia das ultra-estruturas obtidas do microscópio eletrônico, fotomicrografia de microscópio normal, contraste de fase e imunofluorescência, macro e microfotografia, as fotografias com o uso de objetivas grande angulares, normal e teleobjetivas. Algumas disciplinas, como ecologia, bioquímica, biofísica, estatística sociologia, alimentos e alimentação, economia e extensão rural, raramente utilizam recursos visuais e os alunos sugerem que algumas disciplinas como ecologia, sociologia, economia e extensão rural, com estes recursos poderiam exercitar melhor o olhar, aguçando o senso crítico e assim as aulas tornariam mais dinâmicas, discursivas e reflexivas.

A Universidade Estadual de Londrina oferece cursos em fotografia para os alunos de pós-graduação nos níveis de mestrado e doutorado na área biológica e afins, visando uma qualificação técnica cada vez mais aprofundada, que irão auxiliar na apresentação do seu trabalho de tese, em eventos científicos e nas ilustrações das publicações em revistas e livros. A fim de esclarecer o que é tratado nesses cursos eles serão descritos a seguir:

2PIV298 - Tópicos especiais em sanidade animal: Oficina fotográfica aplicada a Ciência Animal

Ementa da Disciplina: Importância e os objetivos da linguagem científica da comunicação visual na Ciência Veterinária. Os tipos de equipamentos fotográficos e recursos empregados nestes registros de produção científica. A utilização de ferramentas integradas com os equipamentos fotográficos. A ética e os direitos autorais na documentação fotográfica científica.

\section{MIB010 - Fotografia aplicada à microbiologia}

Ementa da Disciplina: Micrometria: desenho em câmara clara. Fotografia preto e branco e colorida. Revelação e fixação. Técnicas de fotografia normal, "close-up", macro e microfotografia. Processo de revelação de filmes preto e branco, "slides" coloridos, papéis fotográficos. Documentação científica por cópias, ampliações, transposições e montagens fotográficas.

2PIV260 - Documentação fotográfica macro e microscopia II

Ementa da Disciplina: Documentação fotográfica de peças anatômicas e lesões macroscópicas de animais de experimentação e pesquisa. Fotomicrografia de exames histopatológicos, esfregaços sanguíneos, culturas e agentes etiológicos provenientes destes animais.

2PIV259 - Documentação fotográfica macro e microscópico I

Ementa da Disciplina: Documentação fotográfica de peças anatômicas e lesões macroscópicas de animais oriundos da rotina. Fotomicrografia de exames histopatológicos, esfregaços sanguíneos, culturas e agentes etiológicos provenientes destes animais.

2PIV350 - Documentação fotográfica macro e microscópico I

Ementa da Disciplina: Câmeras fotográficas, filmes coloridos ou preto e branco, slides. Fotografia digital e suas vantagens. Documentação fotográfica. $\mathrm{O}$ assunto em destaque. 
2PIV351 - Documentação fotográfica macro e microscópico II

Ementa da Disciplina: Recursos audiovisuais. O auxílio e programas por computador. Fotografia histopatológica.

As duas primeiras disciplinas (2PIV298 e 2MIB010) são ofertadas para dois níveis: mestrado e doutorado dos cursos em Ciência Animal e Microbiologia. As outras quatro disciplinas (2PIV259, 2PIV260, 2PIV350 e 2PIV351) são para alunos da Residência em Medicina Veterinária Preventiva e Patologia Animal.

Os docentes responsáveis pelas disciplinas de fotografia têm capacitações em suas respectivas áreas de atuações, mas a formação na fotografia foi obtida pela experiência adquirida ao longo da sua atividade de capacitação, com orientações de referencias escritas e de outras profissionais que atuam com a documentação visual e fotográfica da área educacional da instituição.

\section{Reflexões sobre a Fotografia e a Prática Docente}

Fotografar é um ato pessoal e intransferível, resultante da imprescindível interação entre aquele que opera a câmara e o conteúdo da cena, do campo ou do espécime fotografado. A fotografia como instrumento de pesquisa tem de ser produzida pelo próprio pesquisador, dentro de sua área de conhecimento. Há uma interação entre a postura do pesquisador fotógrafo com a realidade em estudo que faz parte da própria técnica de pesquisa empregada e os procedimentos de realização da fotografia de campo influem tanto na forma quanto no conteúdo do material obtido e na própria pesquisa em si. Segundo Guran (1998), a matéria prima da fotografia é a face visível da realidade que está em permanente movimento, e a função do fotógrafo é contemplar esse movimento e decidir sobre aquilo que é cientificamente significativo e captá-lo numa fotografia. Então fotografar é atribuir e reconhecer valor em um determinado aspecto de uma cena, que tem de ser evidente e claro ao primeiro olhar sobre a fotografia e isto só é possível quando o pesquisador fotógrafo desenvolve atividade e tem conhecimento e identificação com o conteúdo da matéria. Ainda, seguindo a mesma linha de Guran, uma imagem só é rica em significado na medida da capacidade do pesquisador, do educador e do discente de perceberem suas nuanças de representação da realidade e para que haja resultados positivos, é preciso que a foto seja eficiente na sua função de recolher e transmitir informações e isto depende da qualidade da foto.

A potencialidade da fotografia é a de destacar um aspecto particular que pode ser indicado com o uso de flechas ou letras por este se encontrar diluído em um vasto seqüencial campo de visão, explicitando, através de escolha do momento e do enquadramento, a singularidade e a transcendência de uma cena ou campo visual. A fotografia passa a ser um instrumento visual real do espécime em estudo que está acontecendo naquele momento. Para reconhecer os elementos em estudo são necessárias informações descritivas bem como relacioná-las com a figura do objeto que se está representando na fotografia. Sontag (1981), afirmou que toda fotografia contém múltiplas significações; com efeito, ver algo em forma de fotografia é deparar-se com um objeto potencialmente fascinante. A grande lição da imagem fotográfica está em poder afirmar: “Ali está uma superfície. Agora pense - ou melhor, sinta, intua - no que possa estar do outro lado dela, e como seria a realidade se fosse assim". Esta prática, no entanto nunca irá substituir uma visualização e a experimentação a campo; ela simplesmente irá registrar a presença do objeto em estudo no campo pelo pesquisador e professor, que trará esta informação em sala de aula. Quanto mais destas informações forem fornecidos aos alunos, estes poderão ter mais facilidades nos reconhecimentos dos problemas que estão atingindo os animais, o homem e o meio ambiente e assim promover o aumento de produtividade e o bem estar dos animais e valorização profissional. 
Para fazer as afirmações a seguir, Achutti (1998) usa as palavras de Guran ao dizer que a fotografia e as Ciências Sociais nasceram aproximadamente na mesma época, e desde o início tiveram em comum o interesse pela vida social. Torna-se preocupante quando docentes que ministram disciplinas como Sociologia e Extensão Rural (35\%), Administração e Economia Rural (25\%) e estes não trazem informações imagéticas do homem e seus problemas no campo e as discussões em salas de aulas passam pelas meras impressões pessoais, não auxiliando os alunos nas reflexões que podem ser desenvolvidas através das fotos obtidas no campo de atuação. A reflexão científica dever começar no momento mesmo da tomada da foto, desde que sua produção se dê dentro de padrões de rigor e de atenção de todos os demais procedimentos de pesquisa, não importando a sua natureza, se científica, artística ou social.

\section{Aspectos da Linguagem Fotográfica}

Segundo Camargo (1997), a linguagem fotográfica é formada por todos os elementos que constituem as fotografias e que vão determinar suas características sejam ópticas, mecânicos, químicos ou plásticos. É através deles que a fotografia se realiza e, conseqüentemente, se expressa.

$\mathrm{Na}$ Medicina Veterinária as objetivas grandes angulares e de $50 \mathrm{~mm}$ são as mais utilizadas, principalmente quando se desenvolve estudos com o meio ambiente e o seu entorno, como nas disciplinas de ecologia, sociologia, epidemiologia, forragicultura e produção animal (bovinocultura, suinocultura, avicultura, ovinocultura, caprinocultura, aqüicultura, eqüinocultura). As teleobjetivas são mais utilizadas em situações que não permitem uma aproximação dos espécimes em estudos como, por exemplo, animais silvestres e de zoológicos. Na macrofotografia, o uso das objetivas macro, micro e close-up são meios de aproximação dos espécimes constituídos, principalmente nos estudos parasitológicos com pequenos artrópodes, como ácaros e insetos, também nos estudos das caracterizações das colônias de bactérias e fungos, nas descrições de lesões, alterações e anomalias encontradas nos animais nas clínicas médicas, cirurgias e necropsias. A bioética não permite mais a utilizações de animais vivos para demonstrações de técnicas operatórias nas aulas práticas e assim o uso de fotografia e vídeo tornou meios não cruentos que permitam aos alunos o acesso destas diferentes abordagens das técnicas cirúrgicas.

A fotomicrografia pode ser obtida pelo uso de microscópio normal e pelo esteroscópio, é um processo fotográfico empregado nos estudos estruturais dos tecidos como nos estudos morfológicos dos tecidos vivos e tecidos fixados e corados. A qualidade da foto está diretamente relacionada com a qualidade óptica do microscópio. Este microscópio pode estar acoplado aos acessórios que permitem a verificação da reação de imunofluorescência, contraste de fase e contraste diferencial de interferência, muito utilizado na visualização da superfície das espécimes. Também é pré-requisito o conhecimento do princípio e o funcionamento operacional dos microscópios. Estas fotos podem ser realizadas com a utilização de filme $35 \mathrm{~mm}$ em cromo, colorido e preto e branco; e ainda a captura de forma digital. Muitas vezes o registro fotográfico precisa de parâmetros biométricos e para essa função os pesquisadores professores utilizam a micrometria linear e a micrometria indireta com o microscópio acoplado a uma câmara clara, recurso este empregado na mensuração de estrutura ou do espécime que se apresentam morfologia anatômica irregulares e curvas.

Em consulta ao depositário dos trabalhos de teses desenvolvidas junto ao programa de pósgraduação em Ciência Animal, da Universidade Estadual de Londrina, no período de 1999 a 2007 , totalizando 139 trabalhos, sendo 125 no nível de mestrado e 14 de doutorado, foram encontradas 86 teses que não utilizaram a fotografia e 53 que fizeram o uso da fotografia nos seus trabalhos. Dessas, 41 eram fotografia obtidas de objetiva 
normal e grande angular; 69 fotos com o emprego de macrofotografia e 96 de fotomicrografia, na sua grande maioria na área de anatomia patológica; e 116 para registrar bandas de natureza protéica para identificação de bactérias e protozoários e em poucos casos o uso de microscopia eletrônica para verificação de ultra-estrutura e contraste negativo para os estudos de identificação de agentes virais. Também foi verificado que as apresentações destes trabalhos de teses, na sua maioria, há a inserção de figuras fotográficas, mesmo em áreas onde não há nenhuma inserção de fotografia nos trabalhos de teses entregues junto ao programa, como a área de produção animal.

\section{O Desenvolvimento do Olhar pelo Retângulo da Câmera Fotográfica}

Machado (1984), diz que toda fotografia, seja qual for o referente que a motiva, é sempre um retângulo que recorta o visível. Flusser (2002) considerou a imagem técnica como produto indireto, isto é produzido por aparelho e pós-histórica, que é o processo circular que retraduz textos em imagens e esta sucede ao texto altamente evoluído. Ele considera-a dificilmente decifrável pela razão curiosa de que aparentemente não necessita ser decifrável porque o pesquisador fotógrafo reconhece de forma automática pela presença do significado que são unidos por cadeia ininterrupta de causa e efeito. $\mathrm{O}$ caráter objetivo das imagens técnicas faz com que seu observador as olhe como se fossem janelas, e não imagens. Nem sempre acontece como mencionou Flusser (2002) o pesquisador fotógrafo não é um caçador de imagens, existe sim uma decisão última, que é apertar o gatilho e registrar uma cena jamais vista. O observador confia nas imagens técnicas tanto quanto confia em seus próprios olhos. E esta confiança em um grau mais avançado pode ocorrer a eliminação de textos e o que não podemos concordar, a imagem deve ser subordinada ao texto. Uma vez que todas as imagens técnicas precisam ser decifradas por quem deseja captar-lhes o significado, neste caso os alunos. Quando as imagens técnicas são decifradas, surge o mundo conceitual como sendo o seu universo de significado. Mas a imagem técnica não tornou visível o conhecimento científico e tampouco irá massificar. Os textos científicos desembocam nas imagens técnicas, deixam de fluir e passam a circular nelas e fundir a sociedade em massa amorfa.

A trajetória histórica da fotografia científica tem o seu início com o surgimento da fotografia, e ela apresentou em preto e branco. A construção da imagem técnica é menos filosófica que a proposta descrita por Flusser (2002), porque a ciência vivenciou por um longo período esta situação limite e com o desagradável intermediário e ansiava pela vinda das cores. Codificar as imagens e decifrálas é descobrir o que o conceito significa, porque na fotografia se amalgamam duas intenções codificadoras: a do fotógrafo e a do aparelho. De acordo com Flusser (2002), o fotógrafo visa eternizar-se nos outros por intermédio da fotografia. O aparelho visa programar a sociedade através da fotografia para um comportamento que lhe permita aperfeiçoar-se. A fotografia como valor está na informação que transmite. O fotógrafo pesquisador prepara a sua imagem para ilustrar o seu trabalho textualizado e isto ocorre em função de norma de publicação e editoração do meio de veículo e permitindo assim alcançar muitos receptores.

\section{A Técnica Fotográfica na Microscopia Eletrônica}

A microscopia de luz utiliza-se de radiação de ondas luminosas, sendo esta refratada através de lentes de vidro. O campo microscópico aparece brilhantemente iluminado e os objetos estudados se apresentam mais escuros. Geralmente os microscópios deste tipo produzem um aumento útil de aproximadamente de 1.000X. O comprimento de onda da luz utilizada nestes microscópios varia entre 400 e 700nm. O melhor poder resolvente conseguido é de $0,2 \mathrm{~mm}$. Na microscopia eletrônica a radiação 
empregada é a de feixe de elétrons, sendo esta refratada por meio de lentes eletrônicas. Para isso o espécime necessita de fixação em tetróxido de ósmio e glutaraldeido e inclusão em Araldite para exame em microscopia de transmissão e para microscópio de varredura, o espécime deve ser revestido por um material de densidade elevada (com grande numero atômico) e de boa condutividade elétrica; dessa maneira, evita se os efeitos das cargas e descargas do espécime, assim o material examinado resiste a este bombardeio de elétrons. Para isto todos os microscópios eletrônicos são dotados de canhão eletrônico que é a fonte de iluminação do aparelho que consiste em um pequeno fragmento de fio em forma de V. Uma alta voltagem é aplicada neste filamento, fazendo com que uma corrente flua através dele e o incandesça, emitindo elétrons. Este tipo de microscópio produz aumento útil de 200.000 a 400.000X, sendo seu poder resolvente cerca de 100 vezes maior que o do microscópio de luz. A melhoria do poder resolvente do microscópio eletrônico está diretamente relacionada ao curto comprimento de onda apresentado pelos raios eletrônicos utilizados para ampliar o espécime e a maior abertura numérica obtida em função da diminuição da distancia focal.

Basicamente o microscópio eletrônico pode ser classificado em dois tipos: de transmissão e de varredura. O microscópio de transmissão (MET), também chamado de microscópio eletrônico direto, pelo fato da imagem do espécime ser formada simultaneamente à passagem do feixe de elétrons através dele. O emprego deste microscópio é difundido nos estudos de morfologia celular, aspectos gerais das organelas e a interação de parasitas e microorganismos com as células, fornecendo informações sobre alterações e efeitos citopáticos. Os melhores resultados obtidos para amostras biológicas situa-se na faixa de $01 \mathrm{~nm}$. No microscópio de varredura (MEV) um feixe de elétrons extremamente estreito é usado para varrer o espécime, isto é, ele é movido para diante e para trás enquanto passa através do espécime. O feixe tem vários efeitos sobre o espécime, dos quais o principal é que faz com que o próprio espécime emita elétrons. A imagem é constituída em seqüência, no tempo, à medida que o espécime é varrido. O emprego deste microscópio tem sido nos estudos de taxonomia e classificações de insetos, ácaros, fungos e nos estudos das superfícies celulares e pela análise de raios-X pode se estudar a composição de inclusões encontrada no interior de microorganismos nos estudos de monitoração ambiental.

A linguagem fotográfica observada nos estudos da microscopia eletrônica não difere absolutamente daquela efetuada na fotografia cientifica, porque ela também pertence á categoria e também registra objetos estáticos. A tecnologia caminha a passos largos que muito se confunde com a fotografia eletrônica, e os equipamentos de microscopia eletrônica são dotados de acessório capaz de observar a ultra-estrutura minúscula como o átomo e também registrar o processo de hibridização entre o ser humano e a máquina, esta menor que célula viva, capaz de percorrer vasos sanguíneos com velocidade impressionante. Santaella (2003) conceitua a nanotecnologia como uma técnica para o design de maquinas muito pequenas que podem ser programadas para operar em ambiente como o corpo humano.

Criando máquinas a partir de moléculas, as nanotecnologias podem combater doenças, aumentar a performance física ou evitar envelhecimento. Assim sendo, a nanotecnologia intervém no nível do carbono, mudando os fundamentos da matéria na sua essência atômica e molecular. Essa expansão da tecnologia para o mundo interior em uma escala de complexidade e ínfima miniaturização pode resultar em imagens abstratas e surrealistas, que chamam a atenção pela aparência e textura das estruturas presentes nas imagens que parecem flutuar no espaço como um corpo imaterial, produz a sensação de estarmos diante de outra realidade. Machado (1984) chama de ruptura da normalidade comportamental e ruptura de normalidade óptica da perspectiva que parecem se corresponder mutuamente; ambas perfuram e corroem o solo firme da ideologia da 
normalidade que se cristaliza em nossos gestos tanto quanto em nossas retinas, mas na fotografia científica trata-se de um registro real dentro da normalidade óptica.

Assim, acreditamos que a presença da fotografia no curso de Medicina Veterinária é algo que tem contribuído não só na formação profissional, como também tem colaborado com a humanidade, uma vez que torna essas pessoas mais sensíveis ao mundo à sua volta. Achutti, (1998) disse acreditar na proximidade da Fotografia com a poesia, na forma semelhante que ambas têm de tocar a alma humana. Sobre alma e fotografia, fiquemos com algumas palavras poéticas do professor Etienne Samain (in Achutti, 1998):

Pequena queimadura de luz sobre uma superfície sensível (como alma) - os nitritos de prata, pele e película ao mesmo tempo - a fotografia é, na sua materialidade, tanto uma ferida como uma cicatriz, uma fenda aberta no tempo, uma rachadura no espaço, uma marca, um rastro, um indício. Corte e golpe, ela é essa superfície de signos múltiplos e complexos, aberta a um passado que já não existe mais e a um futuro que não chegou a ser. As fotografias são tecidos, malhas de silêncio, as pequenas peles, as películas da nossa vivência. As fotografias são memórias e confidências.

\section{Referências}

ACHUTTI, L. E. R. Ensaios (sobre o) fotográfico. Porto Alegre: Unidade Editorial, 1998.

CAMARGO, I. A. Reflexões sobre o pensamento fotográfico. Londrina: EDUEL, 1997.

FLUSSER, V. Filosofia da caixa preta: ensaios para uma futura filosofia da fotografia. São Paulo: Relume Dumará, 2002.

GURAN, M. A fotografia eficiente e as Ciências Sociais. In: ACHUTTI, L. E. R. Ensaios (sobre o) fotográfico. Porto Alegre: Unidade Editorial, 1998.

MACHADO, A. A ilusão especular: introdução à fotografia. Rio de Janeiro: Brasiliense, 1984.

SANTAELLA, L. Culturas e artes do pós-humano: da cultura das mídias à cibernética. São Paulo: Paulus, 2003.

SONTAG, S. Ensaio sobre a fotografia. Rio de Janeiro: Arbour, 1981. 
